\title{
Cellulose Acetate and Cardanol Based Seed Coating for Intraspecific Weeding Coupled with Natural Herbicide Spraying
}

\author{
Marco Friuli ${ }^{1}\left[\right.$ D Paola Nitti $^{1} \cdot$ Luca Cafuero $^{1} \cdot$ Alessia Prete $^{1} \cdot$ Muhammad Shajih Zafar $^{1} \cdot$ Marta Madaghiele $^{1}$. \\ Christian Demitri ${ }^{1}$
}

Published online: 14 July 2020

(c) The Author(s) 2020

\begin{abstract}
Agricultural pesticides can become persistent environmental pollutants and their use is destined to be reduced. Consequently, weed control is shifting to green products and strategies. A combined approach, made of pelargonic acid based herbicide spraying and interspecific competition (i.e. seeding of plants species competing for growth against weeds) could boost the weeding effect. In case of the contemporary seeding and spraying, needed to reduce costs, seed coating is necessary as barrier to herbicide toxic effects but, at the same time, the coating has to be endowed with the right features to allow germination. This work aims to verify the feasibility of using cellulose acetate/cardanol (CA/Card) as seed coating polymer-plasticizer blend and to identify possible relationship between material features and germination rate. For these purposes, untreated and pelargonic acid herbicide treated coated seeds coated through solvent evaporation methods (CA/Card ratios from 0/0 to 100/0) were subjected to germination test. Coatings were characterized through SEM, EDX, media uptake, DSC and mechanical analysis with and without conditioning in seeding conditions. Germination test showed that 70/30 seeds, treated and untreated with herbicide, presented the best germination rate. Germination assays showed that coating presence reduced and slowed (without stopping) seeds germination equally with and without herbicide treatment. Consequently, was possible to conclude that CA/Card coatings allowed germination and presented a barrier effect against herbicide. Thus coating resulted suitable for seed coating in herbicide spraying/interspecific combined applications. No strong correlations were found between material features and germination, but it is plausible to hypothesize that both water absorption and mechanical properties of the coating play an important role and have to be optimized to improve germination rate avoiding difficulty in sprouting. Finally, the study opened a new perspective in the use of cellulose acetate for seed coating from waste sources such as cigarette filters.
\end{abstract}

Marco Friuli

marco.friuli@unisalento.it

1 Department of Engineering for Innovation, University of Salento, "La Stecca" Building, Via per Monteroni, 73100 Lecce, Italy 


\section{Graphic Abstract}

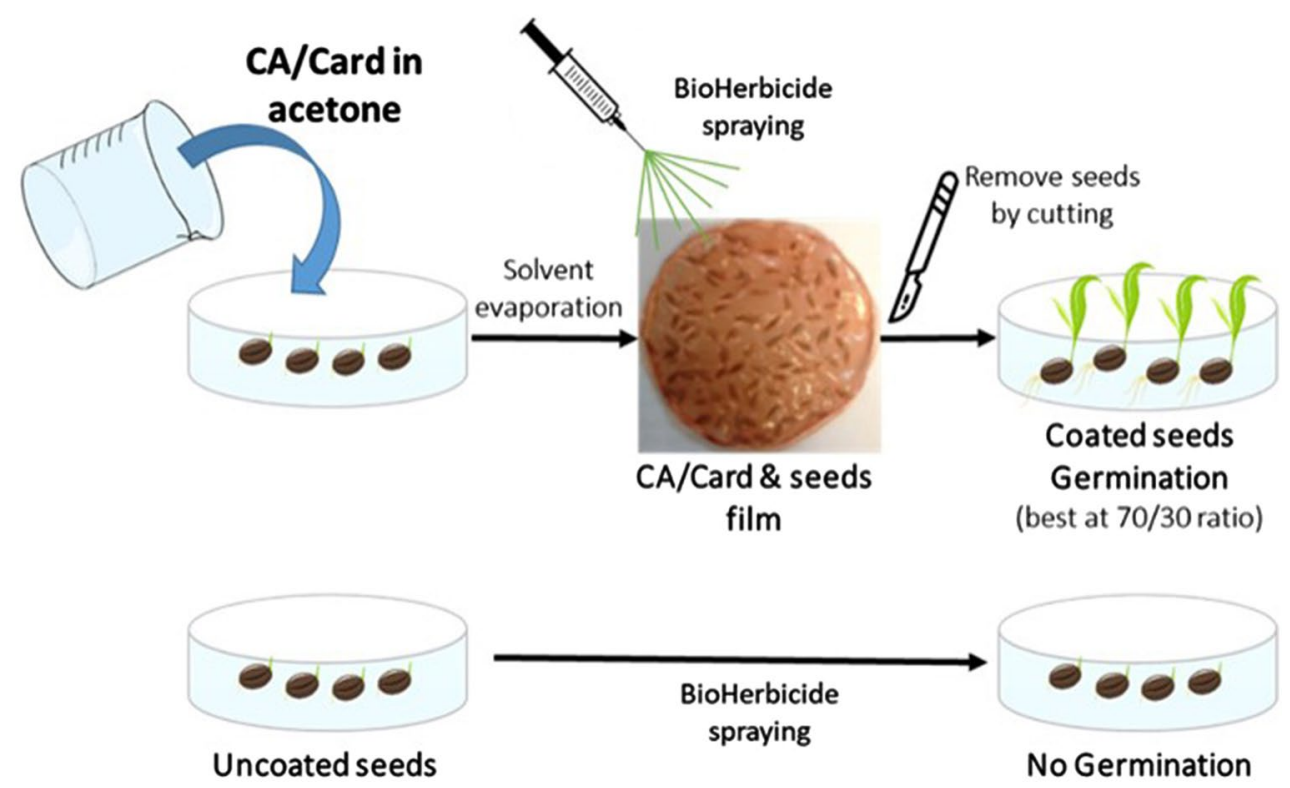

Keywords Cellulose acetate $\cdot$ Cardanol $\cdot$ Seed coating $\cdot$ Bioherbicide $\cdot$ Weeding

$\begin{array}{ll}\text { Abbreviations } \\ \text { GLP } & \text { Glyphosate } \\ \text { CA } & \text { Cellulose acetate } \\ \text { Card } & \text { Cardanol } \\ \text { CA/Card } & \text { Cellulose acetate and cardanol ratios } \\ \text { SD } & \text { Standard deviation }\end{array}$

\section{Introduction}

Herbicides are compounds used mainly to eliminate not selectively invasive weed species growing in public areas for aesthetic or practical reasons (e.g. from sidewalks, pavements and railways) or competing for nutrients and sunlight in crops or livestock farms. Generally, one the main herbicides drawbacks, is their persistence as environmental pollutants. For example, glyphosate (GLP, probably the most employed herbicide) is under particular scrutiny because of its possible environmental and health risk, to the point that its use is going to be reduced from almost all the EU countries starting from 2023 [1].

Consequently, in the last years, the operative control of infesting annual grasses explored more environmental and health safe alternative products and strategies in order to substitute traditional non-discriminating herbicides. Among new products [2-4] water based bioherbicides (e.g. pelargonic acid) or essential oils (e.g. Asteraceae oil) [5-15] are already commercially available. Differently, some weed management strategies are still almost unexplored; one of these is the so-called interspecific competition. This action, is carried out through the seeding of some plants species able to reduce weeds proliferation by subtracting water and space available for their growth (i.e. competition) [16-19]. Consequently, is still similarly unexplored the combined use of bioherbicide and interspecific competition. The coupling could enhance the weeding through the synergistic effect of the two strategies but only providing that seeds are protected from chemicals toxic action, for example by using a seed coating.

Artificial seed coating is the application of exogenous materials on the surface of the natural seed coat. A seed coating can contain active substances such as pesticides, micronutrients, soil adjuvants, germination or growth promoters to protect seeds from several pathogenic microorganisms and insects or to promote germination and growth [20]. Coatings are used also to improve seeds handling (e.g. colored coatings to recognize species) and storage [21]. Several materials have been used for seed coating, among them vinyl acetate homopolymer, methylcellulose, polyethylene glycol, chitosan, polyvinyl alcohol, ethyl cellulose, polyvinyl acetate and arabic gum [21]. In 2020 the global seed coating material market (polymers, colourants, and bulking agents) is expected to be about US\$ 1.63 billion and a further growth is possible in the next few years [22-25].

In order to couple chemical herbicide spraying and interspecific competition (coupled action), the coating must be 
not toxic and protect seeds at the initial stages of contact with toxic substances. At the same time, coating materials must allow seed-water contact to start germination and it must gradually degrade to facilitate sprouting and plant structures growth [26-28]. Consequently, some key factors influencing the effectiveness and to take in account for the selection and production of a material for seed coating are: (i) toxic effects on seeds of coating composition and processing; (ii) coatings thickness and mechanical properties (as it should not prevent the escape of the root system and sprout); (iii) its barrier effect against chemicals and water permeation (related both to coating defects and composition) and finally (iv) the coating degradation rate. Additionally, when the herbicides used in coupled action is water based (e.g. pelargonic acid), coating materials have to be not water-soluble. Moving from these principles, cellulose acetate (CA) may be suitable for seed coating in water based bioherbicide spraying coupled with interspecific competition.

CA is a low cost, nontoxic and biodegradable semisynthetic polymer made from renewable sources [29] through acetylation of cellulose with acetic acid (resulting in replacement of acetyl groups for some of the hydroxyl groups of cellulose). CA is mainly used for coatings or as fibers for clothing production or as material for filters preparation (such as cigarette filters) but is still unexplored as seed coating material. CA is soluble in acetone and dichloromethane-methanol (depending on substitution degree) [29]. Consequently, it is possible to obtain sufficiently thin insoluble in water (but degradable) films through low temperature process like solvent evaporation [30]. CA biodegradation starts in presence of water (leading to a temperature dependent deacetylation step by chemical hydrolysis) followed by cellulose degradation by cellulase. Degradation can be fostered by microbial and/or enzymatic action (e.g. degradation in soil) [31-39]. Finally, as for other polymers, it is possible to modify CA properties by the use of plasticizer in order to match the necessary characteristics previously listed.

In the present study, following the "green" approach, a natural plasticizer based on cardanol oil was used. Cardanol (Card) is one of the main organic element (about $30 \mathrm{wt} \%$ ) in cashew nut shells. It is a phenol derivative comprising of a linear unsaturated hydrocarbon as an elastic and hydrophobic long side chain and phenol as an inflexible aromatic part with a reactive hydroxyl group [40-43]. The effect of Card oil as plasticizer has already been tested in the field of composite materials, for example in the Card-based matrix biocomposites reinforced with natural fibers [44].

Finally, as further element of interest in the use of CA as new seed coating material is the possibility to reuse production waste or waste, such as used cigarette filters, as raw material for coating preparation. Cigarette litters, if abandoned in their commercial form in nature, have degradation times over the years [45], releasing polluting substances into the environment as degradation progresses. With the growing awareness of their environmental impact, new strategies for their reuse (for example as fillers in bricks [46]) and new techniques for their washing are always sought. A use in the field of seed coating, would allow their recycling in a useful form and probably easier to bio-resorb as it is used in the form of a thin film in presence of water and microbial/enzymatic action. Furthermore, developing a selective wash that does not eliminate the nicotine inside them, would lead to the realization of bioactive coating.

The main purpose of this study was to verify the feasibility of using CA/Card as seed coating material, in particular when applied as barrier to protect seeds from bioherbicide toxic effects during contemporary herbicide spraying and seeds sowing for interspecific competition applications. Consequently, seeds were coated with different CA/Card ratios prepared by solvent evaporation. Then, germination assay with and without herbicide treatment was performed to evaluate the germination rate among all the CA/Card ratios and to define the more suitable composition by investigating possible negative material or processing effects on seeds germination and the coating barrier effect to herbicide. Furthermore, coatings were characterized to evaluate the relationships between the variation of possible germination influencing material properties (e.g. mechanical, barrier and degradation properties) and performance in germination assay in order to define some key aspects to optimize the material to obtain the best performance.

\section{Materials and Methods}

\section{Materials}

CA (average $\mathrm{Mn} \sim 30,000)$ and Card oil characterized by a purity of $95 \%$, (Card molecular weight from 298 to $304 \mathrm{~g} /$ mole) were purchased respectively from Sigma Aldrich (MO, USA) and Oltremare (Bologna, Italy). Acetone ( $\geq 99.5 \%$ from Merck Life Science, Milan, Italy) was used as solvent for coating preparation. The seeds used, received from Césped Sparring supplied by Semillas Fitò, were part of a specific herb mixture as follows: $30 \%$ Festuca arundinaceafiraces, $30 \%$ Festuca arundinaceagolden gate, 25\% Festuca arundinaceaumbrella, 10\% Lolium, $0.5 \%$ Poacea. The species contained in the batch of tested seeds have the same germination times between them in fact, they are indicated for the creation of garden lawns. The herbicide Finalsan Erbicida Professional by Kollant S.r.l.[Vigonovo (VE), Italy], based on pure pelargonic acid, was used to treat seeds. 


\section{Cellulose Acetate/Cardanol Film Preparation and Seed Coating}

The process of seed coating and for membranes preparation (without seeds) was carried out through solvent evaporation method. $1.5 \mathrm{~g}$ of CA powder and Card oil at different weight ratio (CA/card ratio from 100/0 to 50/50 as reported in Table 1) were mixed in $15 \mathrm{ml}$ of acetone by stirring for $1 \mathrm{~min}$ at $200 \mathrm{rpm}$. The obtained solutions were poured into an $80 \mathrm{~mm}$ diameter glass Petri dish and then 60 random seeds were uniformly placed in each poured solution. The solvent was allowed to evaporate at room temperature in static conditions for about 50 min to obtain the membranes filmed at the bottom of the Petri dish and containing the seeds as reported in Fig. 1. The covered seeds were then removed by cutting them from the membrane. The process for preparation of films without seeds (reported as membranes) followed the same protocol as above but without placing seeds inside the solution. As positive and negative controls were used uncoated seeds reported in table as $0 / 0$ samples, following the same notations of CA/Card coated seeds.

\section{Bioassay}

Germination tests were performed to verify seed viability after the coating process and herbicide treatment. Furthermore, the test aimed to asses which of CA/Card coatings provide better the germination through the comparison between germination rate of untreated and herbicide treated coated seeds.

\section{Germination Test}

The germination rate of coated seeds was assessed through germination test with and without herbicide treatment (from uncoated $0 / 0$ to 100/0 CA/Card ratios as reported in Table 1). For every condition, the germination test was performed in triplicate by sowing seeds in moistened cotton wool. 30 seeds for each ratio were placed inside $80 \mathrm{~mm}$ Petri dishes containing a layer of cotton wool uniformly moistened with $80 \mathrm{ml}$ of distilled water (called germinators, Fig. 2). Only in herbicide treated samples, the seeds were treated with $1 \mathrm{ml}$ of Finalsan 20\% (v/v) herbicide (concentration provided by the manufacturer for treatment of infesting plants) before sealed with parafilm to reduce evaporation. Finalsan was spread on seeds by a syringe nebulizer $(0.03 \mathrm{ml} / \mathrm{seed})$. Both for herbicide treated and untreated seeds, as positive controls were used non-coated seeds untreated with herbicide to verify seeds viability $[0 / 0$ positive control $+(\mathrm{H})$ in Table 1]. In treated condition, a negative control made of uncoated seeds sprayed as above with $1 \mathrm{ml}$ of Finalsan 20\% $(\mathrm{v} / \mathrm{v})$ was added in order to verify the effect of herbicide on seeds $[0 / 0$ negative control $-(\mathrm{H})$ in Table 1$]$. In addition, for each condition, another germinator containing 30 uncoated pre-treated in acetone seeds was added as control [0/0 acetone $(\mathrm{G})$ in Table 1$]$ in order to evaluate the effect of the solvent on seeds viability. Pretreatment consisted in seeds immersion in acetone for $50 \mathrm{~min}$ (the same time as the coating processing).

All the germinators were placed inside a Binder climatic chamber at $27^{\circ} \mathrm{C}$ and $90 \%$ relative humidity (RH) for 15 days and monitored every 2 days. Average germination

Table 1 Coated seeds with different CA/Card ratios (50/50-100/0) and uncoated controls (0/0) tested in germination assay with and without herbicide treatment

\begin{tabular}{|c|c|c|c|c|c|c|c|c|c|}
\hline Samples CA/Card ratio & & & & & & & & & \\
\hline Condition & (A) & (B) & (C) & (D) & (E) & $(\mathrm{F})$ & Acetone (G) & $\begin{array}{l}\text { Positive con- } \\
\text { trol }(+)(\mathrm{H})\end{array}$ & $\begin{array}{l}\text { Negative } \\
\text { control (-) } \\
(\mathrm{H})\end{array}$ \\
\hline Without herbicide treatment & $100 / 0$ & $90 / 10$ & $80 / 20$ & $70 / 30$ & $60 / 40$ & $50 / 50$ & $0 / 0$ & $0 / 0$ & - \\
\hline With herbicide treatment & $100 / 0$ & $90 / 10$ & $80 / 20$ & $70 / 30$ & $60 / 40$ & $50 / 50$ & $0 / 0$ & $0 / 0$ & $0 / 0$ \\
\hline
\end{tabular}

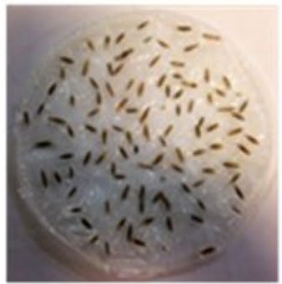

A

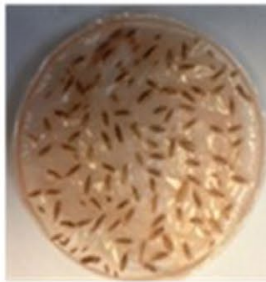

B

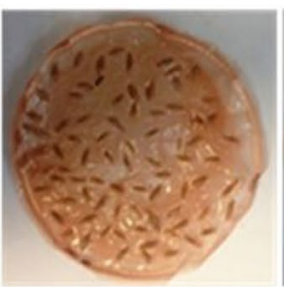

C

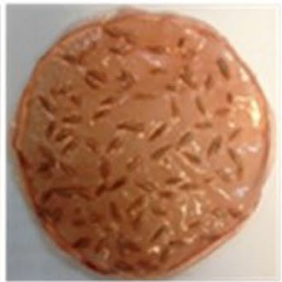

D

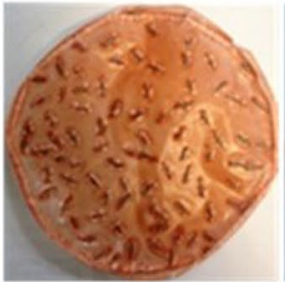

$\mathbf{E}$

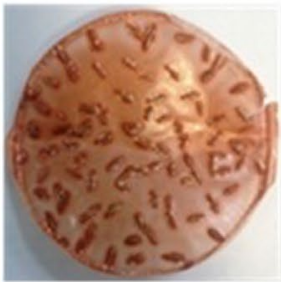

F

Fig. 1 Membranes containing coated seeds at different CA/Card ratios: a 100/0, b 90/10, c 80/20, d 70/30, e 60/40, and f 50/50 


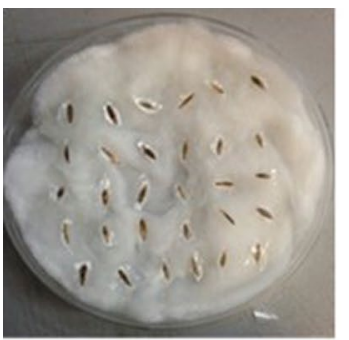

A

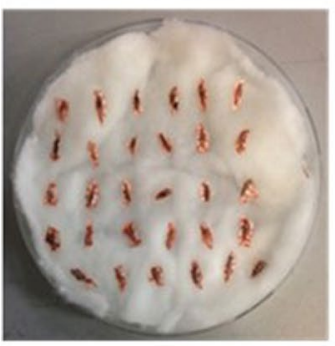

$\mathrm{E}$

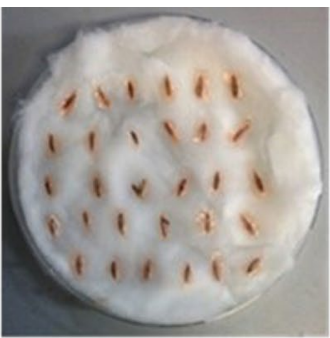

B

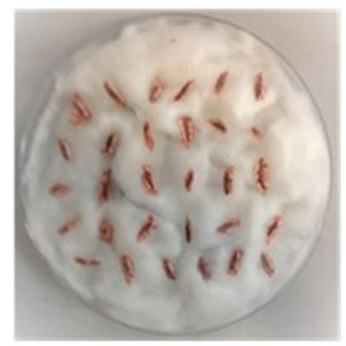

$\mathrm{F}$

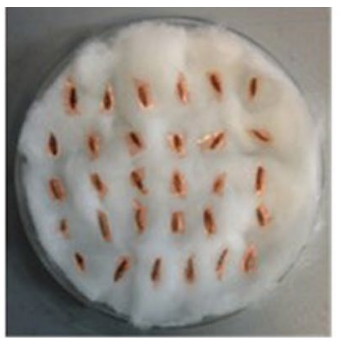

C

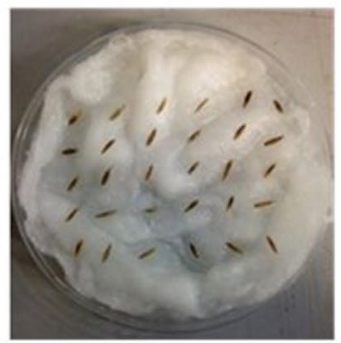

G

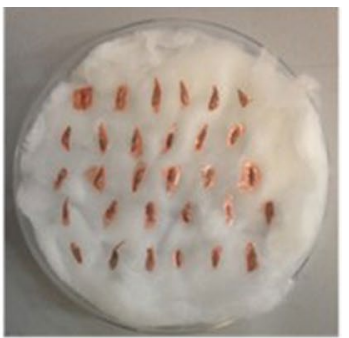

D

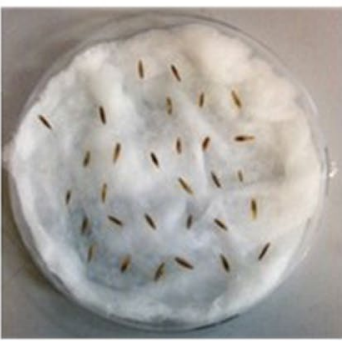

$\mathrm{H}$
Fig. 2 Example of germinators (seeds on moistened). CA/Card ratio: a $100 / 0$, b $90 / 10$, c $80 / 20$, d 70/30, e 60/40, f 50/50, g 0/0 acetone, and $\mathbf{h}$ 0/0 (Control). The seeds were positioned on the moistened cot-

percentage (as germinated seed number/seed number seeded) and germination time (as days of first germination) were evaluated for each sample in Table 1 and error was expressed as standard deviation (SD).

\section{Material Characterization}

Coated seeds were characterized trough media uptake test and morphological analysis. Differently, CA/Card membranes were characterized through thermal and mechanical analysis with and without conditioning in germinators conditions. These tests were performed to verify possible relationship between material properties (and their variation) and germination rate.

\section{Morphological Analysis}

Scanning electronic microscope (by SEM EVO® 40, Carl Zeiss AG) and energy dispersive spectroscopy (EDX, by Bruker Nano XFlash detect 5010 coupled with SEM) analyses were performed on uncoated and coated seeds. CA/Card ratios reported in Table 1 were tested as they are or after media uptake test in order to evaluate the behavior of the coating after the permanence in water. Furthermore, SEM analysis was performed also on samples cross-section to evaluate coating thickness. EDX analysis was performed by electron beam and $20 \mathrm{kV}$ as acceleration voltage, creating an elemental map of uncoated and coated seeds in order ton wool preventing them from touching each other to limit disturbance or contagion of a fungal nature

to detect any defects (uncovered surface parts on seed) through color differences. In particular, defects emerged as purple colored spots on the yellow associated to coated seeds (respectively purple was associated to potassium found on uncoated seed and yellow was associated to coating elements).

\section{Media Uptake Test}

Media uptake test aimed to evaluate both the effects of different CA/Card ratio coatings (from 0/0 to 100/0 CA/ Card ratios) on water absorption and acetone uptake in uncoated $(0 / 0)$ seeds (possible during the coating processing) through single seed daily weight variation measurement [47]. Water uptake was performed by immerging 5 random coated seeds for each CA/Card ratio singularly in a container filled with $30 \mathrm{ml}$ of distilled water at room temperature. Seed were singularly removed from the media, dabbed (to eliminate water excess) and weighed daily until the difference between two consecutive weightings on the same seed was negligible. Daily weights values were averaged and the change in weight, compared to dry samples weights, was expressed as average media uptake percentage [media uptake $\%=((\mathrm{Wf}-\mathrm{Wi}) / \mathrm{Wi}) * 100$, where $\mathrm{Wf}$ is average swelled final weight, $\mathrm{Wi}$ is average dry initial weight $] \pm$ standard deviation (SD). Acetone uptake in uncoated seeds was assessed and expressed as above. 


\section{Thermal Analysis}

Thermal analysis through differential scanning calorimetry (DSC, using Q2000 Series DSC by TA Instruments) was performed on specimens collected from membranes (without seeds) with different CA/Card ratios (from 50/50 to $100 / 0$ ) prepared by solvent evaporation method (as previously described). In order to verify the action of the sowing conditions on the material degradation and water absorption, the tests were carried out on membranes as they are (referred as unconditioned samples) and after 5 days of incubation in climatic chamber in moistened cotton wool at $27{ }^{\circ} \mathrm{C}$ and 90\% HR (germination tests conditions, referred as conditioned samples). During DSC, the samples were subjected to a thermal cycle in nitrogen atmosphere composed of a heating ramp of $5{ }^{\circ} \mathrm{C} / \mathrm{min}$ in the range $25-300{ }^{\circ} \mathrm{C}$ using an empty aluminum crucible as reference.

\section{Mechanical Analysis: Tensile Test}

A mechanical characterization of specimen collected from membranes with different CA/Card ratios (from 50/50 to 100/0) was carried out through uniaxial tensile test at constant temperature by Zwick Roell (100 N load cell, $0.1 \mathrm{~N}$ preload and a constant traverse speed of $0.01 \mathrm{~mm} / \mathrm{s}$ [48]). In order to verify the effects of sowing conditions on mechanical properties, the tests were carried out in triplicate both on unconditioned and conditioned membranes ( 5 days of incubation in climatic chamber in moistened cotton wool at $27^{\circ} \mathrm{C}$ and $90 \%$ HR). The samples were taken from the films with the help of a scalpel and length and thickness were measured with a digital caliper. Each samples group were tested to obtain the (i) average Young's modulus (E), calculated as the slope of the linear elastic region of the stress-strain curve at low strain values (in the range of $1-3 \%)$; (ii) elongation at break ( $\varepsilon_{\mathrm{b}}$, as strain \%) and (iii) tensile strength $\left(\sigma_{\mathrm{b}}\right)$. All the results were expressed as average value \pm SD .

\section{Results and Discussion}

\section{Germination Test}

From the test emerged that germination occurred in positive and acetone uncoated controls and in all coated seeds (treated and untreated with herbicide). In negative control (Control-, 0/0 treated with herbicide) no germination occurred, confirming herbicide reset the germination (average germination $\%=0$, not reported in Fig. 4). In particular, in non-coated (controls) germination occurred within 5 days whereas in coated seeds germination time ranged from 5 days (in 70/30) up to 10 days (in 100/0), as reported in Fig. 3.

As reported in Fig. 4, a substantial reduction in germination rate emerged with the same intensity both for coated seeds (treated and untreated) compared to Control $+0 / 0$. In particular, both for herbicide treated and untreated seeds, the reduction was larger for coatings for higher CA percentages (up to $75 \%$ in $80 / 20$ samples). Differently, a better germination rate emerged in CA/Card ratios in particular, considering treated and untreated conditions, for 70/30 samples. Test showed a reduction (about 15\%, in Fig. 4) in acetone treated seeds, but compared to the effect of coating, reduction could be negligible.

The presence of the coating therefore did not inhibit but reduced and slowed down germination, in particular for higher percentage of CA there was a greater germination delay compared to positive control. On the other hand, herbicide treatment did not affected germination rate and time which presented no substantial differences compared to untreated seeds. Consequently, even though the coating had a negative effect on germination, it acted as barrier against herbicide, preserving seeds viability. Finally, both in herbicide treated and untreated seeds, 70/30 blend resulted the most effective coating.

Due to the lower and slower germination rate in blends with higher CA percentage, it is possible to suppose that
Fig. 3 Average days before first germination for seeds germinating in absorbent cotton at $\mathrm{T}=27^{\circ} \mathrm{C}$ and $\mathrm{HR}=90 \%$ with and without herbicide treatment. Results were reported as days before germination $\pm \mathrm{SD}$

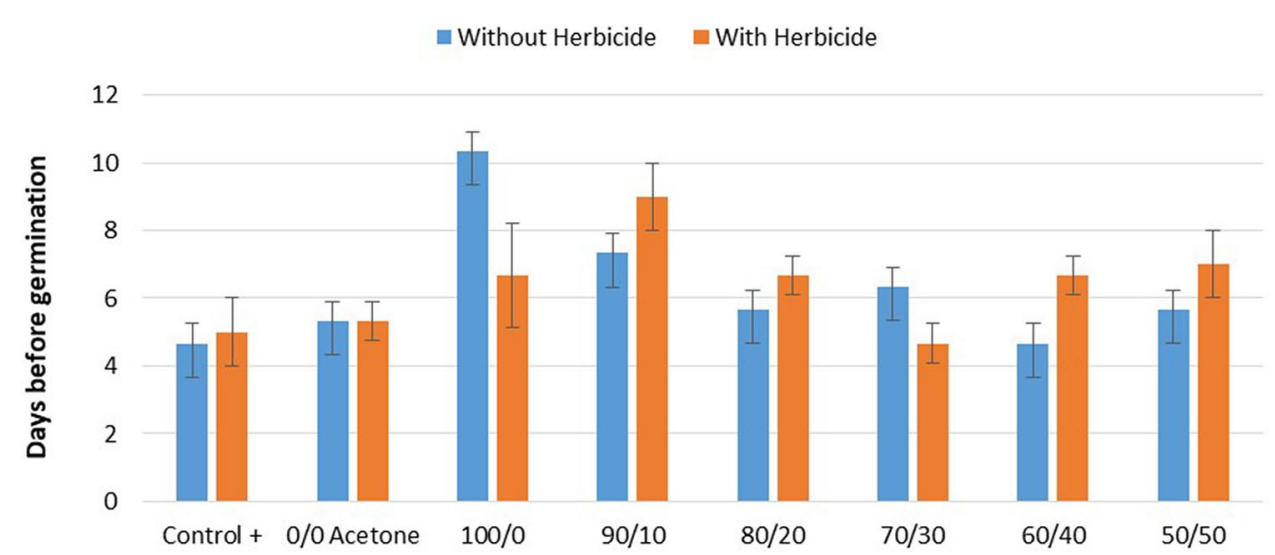


Fig. 4 Results of germination test in absorbent cotton after 15 days of seeding, $\mathrm{T}=27^{\circ} \mathrm{C}$ and $\mathrm{HR}=90 \%$. Left: germination without herbicide treatment. Right: germination with herbicide treatment. $0 / 0$ Control + and $0 / 0$ acetone were untreated with herbicide. Results were reported as average germination $\% \pm \mathrm{SD}$

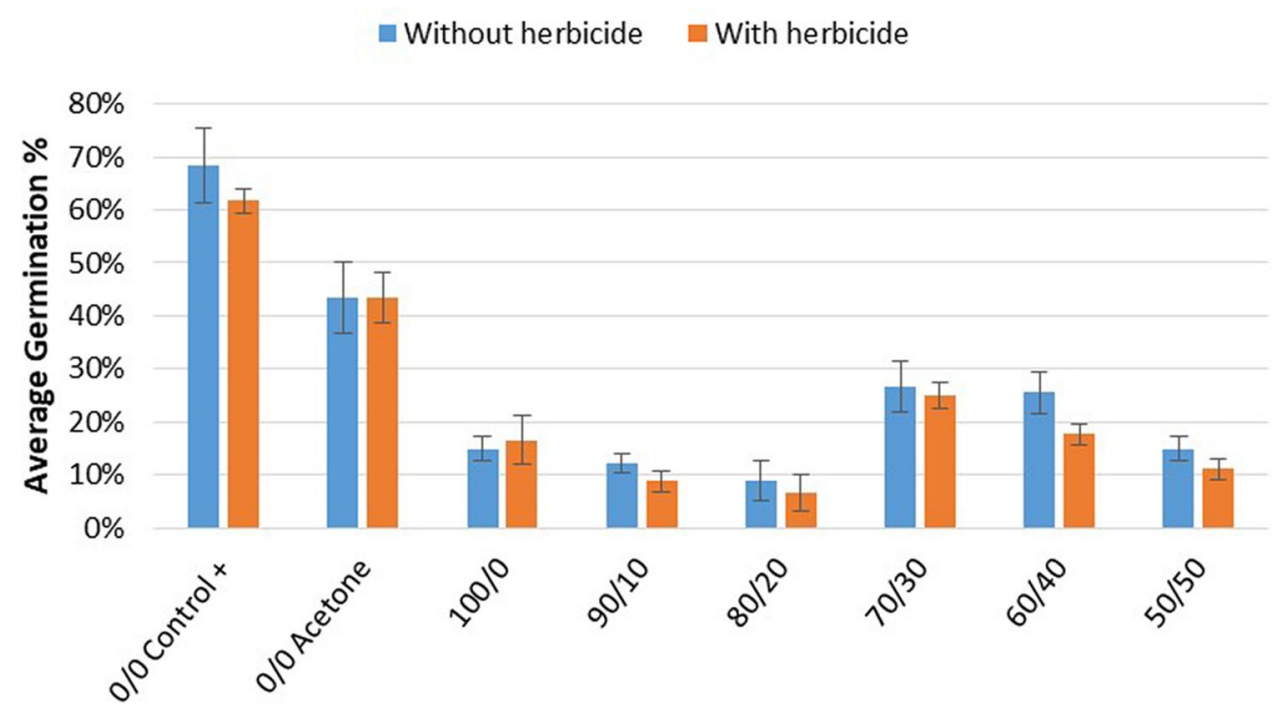

the coating prevents germination by mechanical action and not by toxic action on seeds. In fact, CA amount (in terms of weight) was always the same and its toxic effect should be present in all the samples, including 70/30 that presented a higher germination levels than others. Some other possible explanation to germination test were the presence of not properly or fully impregnated/coated seeds. Considering the absence of germination in negative control, was possible to exclude a lack of herbicide impregnation. Differently, the presence of defect and partially coated seeds was proved by SEM analysis (as showed in morphological analysis, Fig. 5c). Consequently, both treated and untreated seeds were affected equally by defects, the first positively and the second negatively because of the herbicide toxic effect. This should lead to an unreported large difference in germination rate between treated and untreated coated seeds.

\section{Morphological Analysis}

Morphology and coating coverage were evaluated on the entire CA/Card ratios range of coated seeds through SEM and EDX, as they are and after media uptake test. Among them, 100/0 CA/Card ratio seeds were reported in Fig. 5a-d as example.

From SEM observation of the seeds in the entire CA/Card ratios range and in particular from their cross sections (e.g. Fig. 5a), emerged that seeds were effectively coated. Instead, it emerged that thickness (measured through Zeiss Smart SEM software) was not uniform and from average values of $20 \mu \mathrm{m}$ in the upper side of the seed up to $90 \mu \mathrm{m}$ on the bottom (comparable to those reported in the literature [49, 50]). EDX elemental maps analysis was conducted through the observation of differences in color. Briefly, EDX analysis of uncoated seed (Fig. 5b) showed potassium (in purple) as main seed surface element, on the other hand yellow was related to the presence of coating elements (Fig. $5 \mathrm{c}$, right). Considering the average coating thickness generally found on seeds $(20-90 \mu \mathrm{m})$, K signals from seed beneath the coating cannot be detected from the whole surface area of the seeds but only when a defect or a thinner layer (Fig. 5c, right) were presents on coating. Consequently, the analysis lead to conclude that no systematic defect due to the coating processing were present on coating in all $\mathrm{Ca} /$ Card ratios. Through SEM and EDX analyses (executed as above) performed on coated seeds after water incubation, was observed the constant presence of damages on coating surface similar to that reported in 100/0 CA/Card film (Fig. 5c). The fracture can be probably addressed to a mechanical action (traction) of the swollen seed on the coating. Starting from these results, the membrane characterization tests were chosen to understand the possible motivation behind the germination test results.

\section{Media Uptake}

The water absorption by the seeds is a necessary condition for seed germination and consequently plant formation. The water uptake study of uncoated and coated seeds revealed a water absorption between 60 and $156 \%$ weight gain at day 4 as reported in Fig. 6. As expected, the highest weight gain was obtained for uncoated seeds in water.

From the analysis emerged that (Fig. 6) CA/Card ratio considerably influences the absorption. In particular, CA percentage in the coating improved the amount of water absorption at equilibrium (from $62 \%$ for $50 / 50$ up to $107 \%$ for 100/0 after 4 days) and absorption rate as difference in weight between days 0 and 1 (slopes of the curves). Acetone absorption, considering the difference in density compared to water, was very low and equilibrium was reached within 3 days of incubation, just like all the other samples. CA 
Fig. 5 Example of a SEM cross section of uncoated seed (left) and 100/0 coated seeds (red arrows indicates the coating). On the left SEM micrographs (scale bar 400-600 $\mu \mathrm{m}$ ) and $\times 56$ magnification and EDX analysis (on the right) for b uncoated seed, $\mathbf{c}$ coated seeds CA/Card ratio 100/0 and defects emerging from EDX, and $\mathbf{d}$ broken 100/0 CA/Card coating on seed after media uptake test (Color figure online)
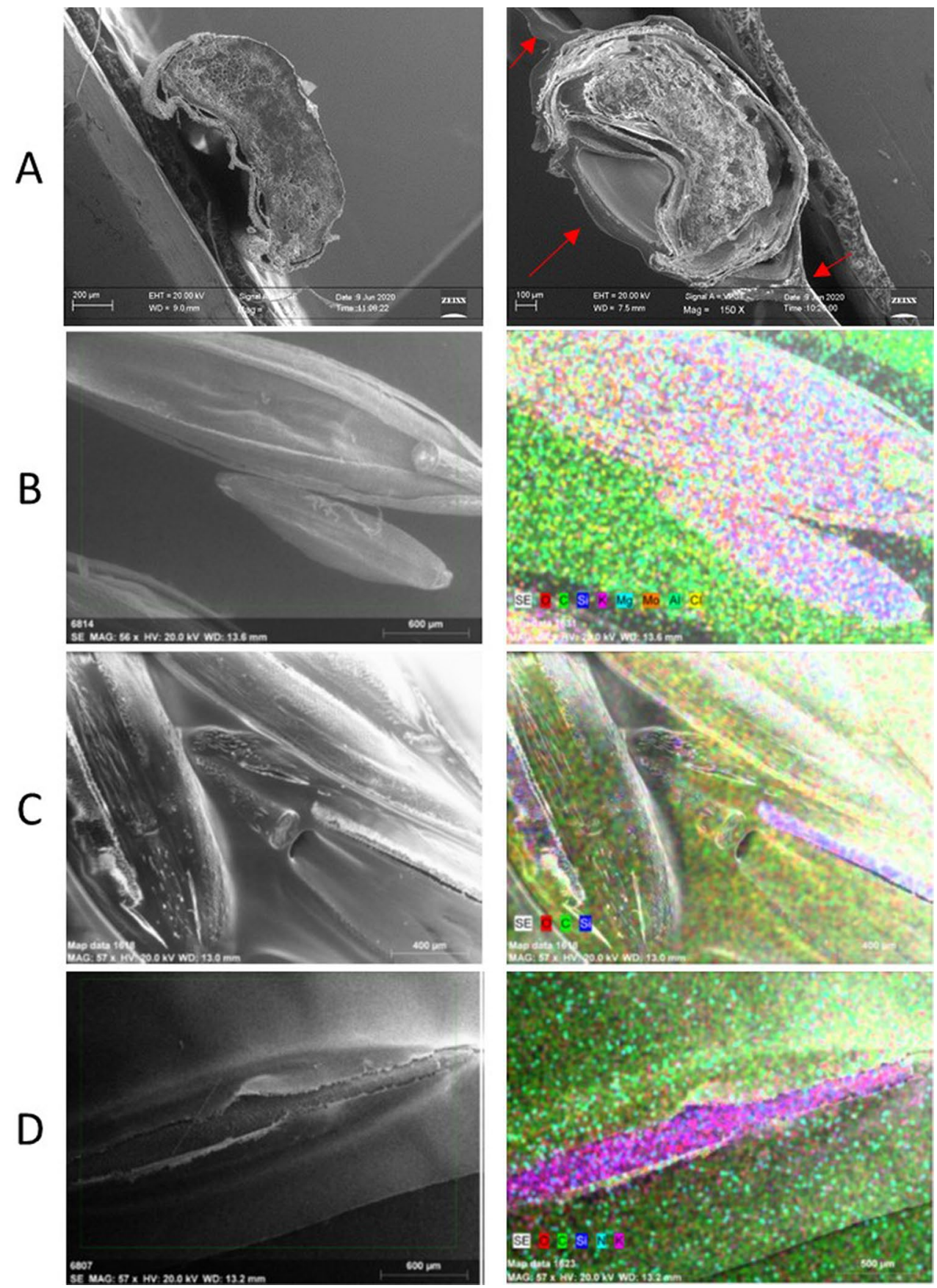

could be related to water absorption behavior. In fact, cellulose in CA is not completely acetylated and any unacetylated hydroxyl groups on CA can act as H-bonding site for water, contributing to water absorption, regardless of the seeds. Nevertheless, considering the irrelevant role in water absorption of the material emerged in membranes water uptake, the absorption behavior could be related to the presence of Card and its effect on water permeability, which could influence the amount of water reached by seeds. In fact, Card has a long carbon chain and its presence could reduce the solubility of water inside the membrane. The higher amount of water in high CA percentage samples should favor germination, but as reported in Fig. 4 this did not take place. Therefore, is possible to speculate that other mechanisms together with water absorption (such as mechanical action of coating) influenced germination rate.

\section{Thermal Analyses}

Differential scanning calorimetry (DSC) was performed on CA/Card specimens taken from membranes as they are (unconditioned samples, Fig. 7a) and after water 


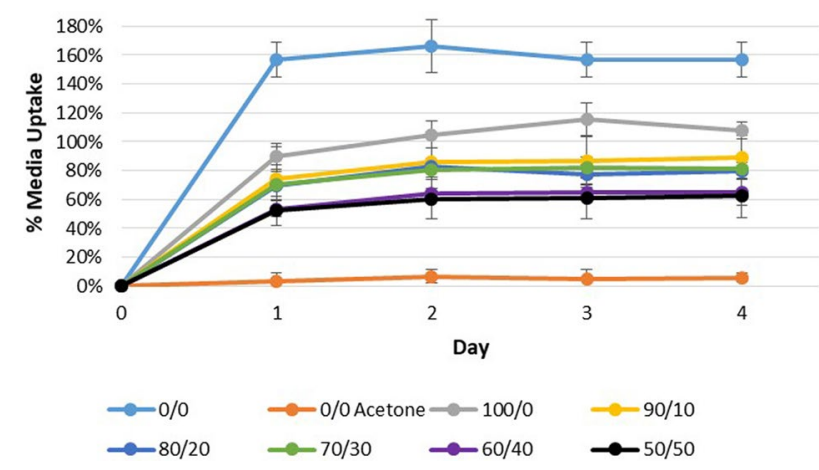

Fig. 6 Water and acetone uptake of CA/Card ratios (0/0-100/0), results are expressed as weight gain $\%$ due to media absorption \pm SD

incubation in moistened cotton wool in climatic chamber for 5 days at $27{ }^{\circ} \mathrm{C}$ and $90 \% \mathrm{HR}$ (conditioned samples, Fig. 7b). All films DSC curves of unconditioned samples presented an endothermic event in a range of temperature between 60 and $76{ }^{\circ} \mathrm{C}$ typical of solvent evaporation [49] and another endothermic related to melting temperature $\mathrm{Tm}$ in a range of $190-220^{\circ} \mathrm{C}$ [51] both unrelated to Card percentage.

On the other hand, clear trend was observed in Fig. 7b and it should be clearly related to the composition of the coating. Considering the effect of Card content on water uptake, it is possible to suppose that peaks reported in Fig. $7 \mathrm{~b}$ were related to water evaporation. In fact, differences in peaks dimensions reflected (except for 100/0 and 80/20) the same trend as water absorption (Table 2). Probably, the presence of higher cellulose acetate chemically bonded water caused a shift to higher peaks temperatures (Table 2). No evidences of polymer degradation emerged.

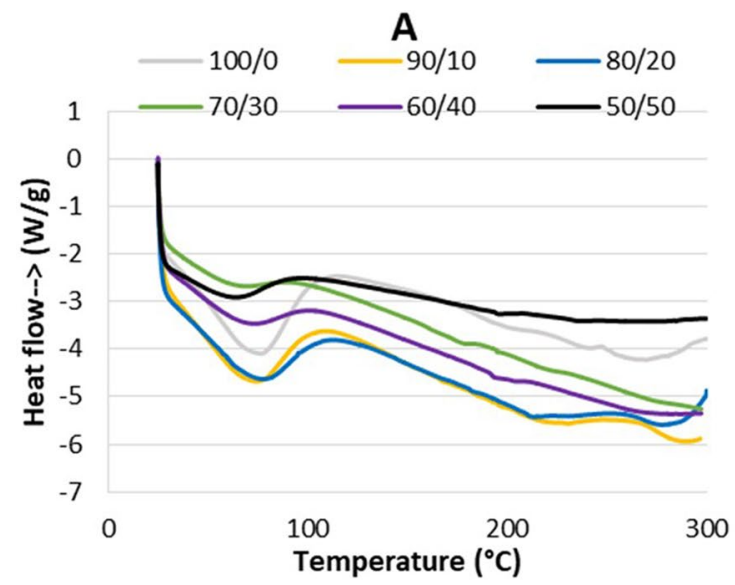

Table 2 Endothermal peak energy and peak temperature (Tp) of CA/ Card membranes as they are (A, unconditioned) and after incubation in moistened cotton wool for 5 days at $27{ }^{\circ} \mathrm{C}$ and $90 \% \mathrm{HR}$ (B, conditioned)

\begin{tabular}{|c|c|c|c|c|c|}
\hline \multirow{2}{*}{\multicolumn{3}{|c|}{$\begin{array}{l}\text { Endothermal } \\
\text { peak analysis } \\
\text { A }\end{array}$}} & \multirow{2}{*}{\multicolumn{3}{|c|}{ B }} \\
\hline & & & & & \\
\hline Composition & $\begin{array}{l}\text { Peak } \\
\text { energy } \\
(\mathrm{J} / \mathrm{g})\end{array}$ & $\mathrm{Tp}\left({ }^{\circ} \mathrm{C}\right)$ & Composition & $\begin{array}{l}\text { Peak } \\
\text { energy } \\
(\mathrm{J} / \mathrm{g})\end{array}$ & $\mathrm{Tp}\left({ }^{\circ} \mathrm{C}\right)$ \\
\hline $50 / 50$ & 20 & 60 & $50 / 50$ & 67 & 67 \\
\hline $60 / 40$ & 30 & 61.5 & $60 / 40$ & 480 & 81 \\
\hline $70 / 30$ & 38 & 65 & $70 / 30$ & 819 & 96 \\
\hline $80 / 20$ & 35 & 74 & $80 / 20$ & 1534 & 131 \\
\hline $90 / 10$ & 58 & 74 & $90 / 10$ & 1292 & 118 \\
\hline $100 / 0$ & 66 & 76 & $100 / 0$ & 66.7 & 92 \\
\hline
\end{tabular}

\section{Tensile Test}

Tensile test was performed on conditioned and unconditioned specimens collected from membranes from 50/50 to $100 / 0 \mathrm{CA} / \mathrm{Card}$ ratios. It emerged that tensile strength at break $\left(\sigma_{\mathrm{b}}\right)$ and elastic modulus (E) increased with CA percentage in the blend (Table 3; Fig. 8a). Instead, CA/Card films after conditioning presented a reduction of an order of magnitude in and in $\sigma_{\mathrm{b}}$ and elongation at break $\left(\varepsilon_{\mathrm{b}}\right)$ (Table 3; Fig. 8b). In particular, this effect was higher for $80 / 20 \mathrm{CA} /$ Card ratio, due probably to water absorption and its role as plasticizer.

These results may be related to those obtained with the DSC test. In fact, the sample with the greatest endothermic peak (80/20 conditioned sample) also reported the highest values for $\varepsilon_{\mathrm{b}}$. This could indicate that in addition to the ability to absorb water making it available for the seed, another

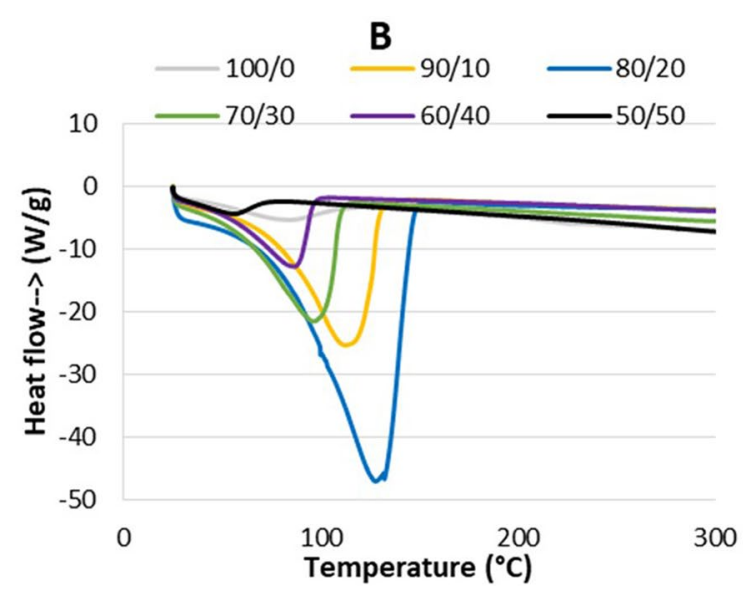

Fig. 7 Comparison of DSC curves of unconditioned CA/Card membranes (a) and conditioned in moistened cotton wool for 5 days at $27{ }^{\circ} \mathrm{C}$ and $90 \% \operatorname{HR}(\mathbf{b})$ 
Table 3 Tensile test parameters: Young's modulus (E), strength at break $\left(\sigma_{\mathrm{b}}\right)$ and elongation $\%$ at break $\left(\varepsilon_{\mathrm{b}}\right)$ of unconditioned $\mathrm{CA} /$ Card membranes (A) and conditioned in moistened cotton wool for 5 days at $27^{\circ} \mathrm{C}$ and $90 \%$ HR (B)

\begin{tabular}{|c|c|c|c|c|c|c|}
\hline \multicolumn{7}{|c|}{ Tensile test parameters } \\
\hline \multirow[t]{2}{*}{$\mathrm{CA} /$ Card ratio } & \multicolumn{3}{|l|}{ A } & \multicolumn{3}{|l|}{ B } \\
\hline & $\mathrm{E}(\mathrm{MPa})$ & $\sigma_{\mathrm{b}}(\mathrm{MPa})$ & $\varepsilon_{\mathrm{b}}(\%)$ & $\mathrm{E}(\mathrm{MPa})$ & $\sigma_{\mathrm{b}}(\mathrm{MPa})$ & $\varepsilon_{\mathrm{b}}(\%)$ \\
\hline $50 / 50$ & $1.6 \pm 0.6$ & $5.2 \pm 0.2$ & $17.4 \pm 2.0$ & $0.3 \pm 0.1$ & $1.9 \pm 0.3$ & $20.7 \pm 4.0$ \\
\hline $60 / 40$ & $1.9 \pm 0.2$ & $9.9 \pm 1.7$ & $24.9 \pm 1.3$ & $0.7 \pm 0.2$ & $4.0 \pm 0.4$ & $31.4 \pm 1.7$ \\
\hline $70 / 30$ & $2.8 \pm 0.3$ & $26.2 \pm 1.0$ & $34.8 \pm 1.6$ & $0.4 \pm 0.1$ & $3.7 \pm 1.5$ & $18.8 \pm 5.6$ \\
\hline $80 / 20$ & $3.0 \pm 0.3$ & $28 \pm 1.00$ & $34.4 \pm 1.0$ & $0.5 \pm 0.1$ & $4.3 \pm 1.4$ & $61.7 \pm 3.9$ \\
\hline $90 / 10$ & $3.4 \pm 0.3$ & $30.0 \pm 1.5$ & $17.1 \pm 1.4$ & $0.8 \pm 0.1$ & $5.1 \pm 1.6$ & $22.7 \pm 3.1$ \\
\hline $100 / 0$ & $5.0 \pm 0.1$ & $47.3 \pm 1.2$ & $14.3 \pm 3.5$ & $1.0 \pm 0.2$ & $8.9 \pm 2.3$ & $24.0 \pm 6.2$ \\
\hline
\end{tabular}

Results are expressed as average value $\pm \mathrm{SD}$
A

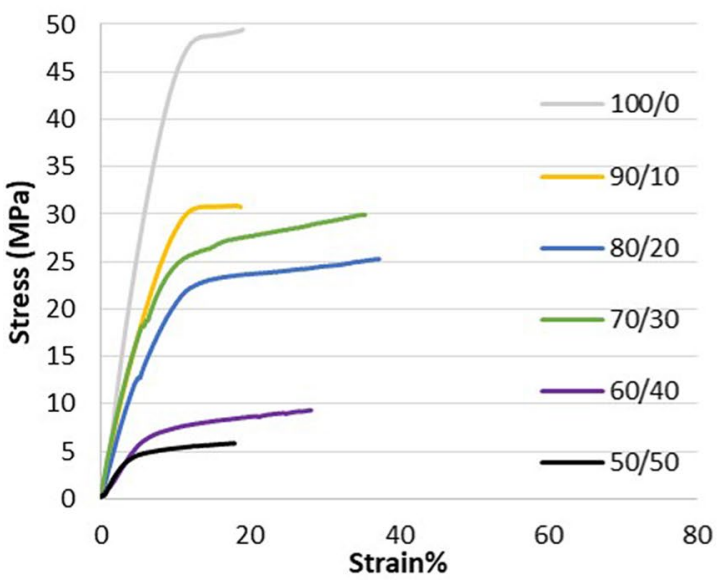

B

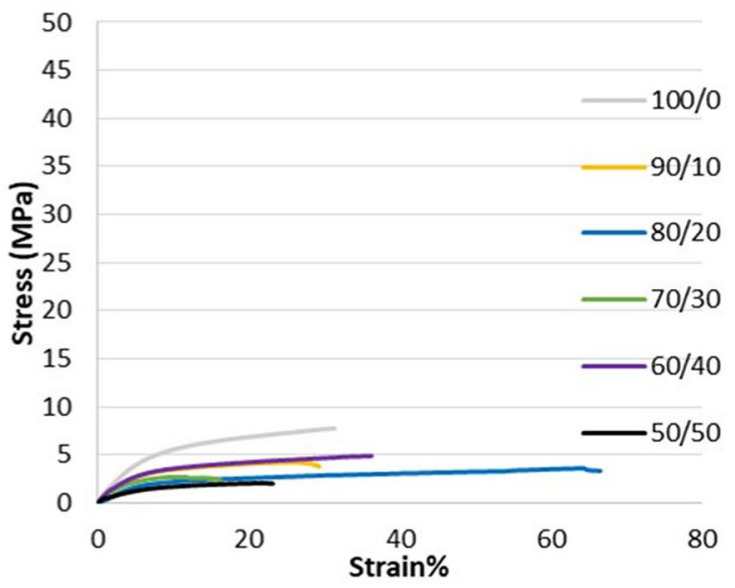

Fig. 8 Stress-strain curves of unconditioned CA/Card membranes (a) and conditioned in moistened cotton wool for 5 days at $27{ }^{\circ} \mathrm{C}$ and $90 \% \mathrm{HR}$ (b)

crucial parameter for germination could be the mechanical properties of the coating and in particular the loss of properties due to water absorption.

\section{Conclusions}

The main purpose of this work was to evaluate the use of cellulose acetate combined with the natural plasticizer cardanol as a novel solution in seed coating, in particular for combined bioherbicides spraying/interspecific competition applications. Germination test was validated by SEM analysis that confirmed the successful outcome of the coating with the solvent evaporation method. Furthermore, it emerged that coating processing, in particular acetone uptake, did not affected significantly the germination rate. Even though coating reduced and slowed germination (as emerged from germination test), it allowed seeds sprouting and had a barrier effect against herbicide treatment (two necessary conditions for combined application). In particular emerged that the best polymer/plasticizer blend were 70/30 and 60/40 CA/ Card ratio. Water presence is commonly known as essential to seeds germination process. Consequently, it was expected coating permeation to water as a material fundamental parameter. Instead, there was no direct proportionality between water uptake and germination: for example $100 / 0$ coated seed had the higher water uptake but not the best germination. Consequently is possible to conclude that mechanical properties played a role in germination. In fact, as emerged from SEM analysis, a possible sprouting mechanism involves coating breakage when stretched by swollen seed, but this is possible only if mechanical properties allow it.

Water absorption in polymers as usual had an important role in mechanical properties variations as emerged from tensile test. Thus, is possible to suppose that best performances in germination are water related but not only in sense of water necessary to seed, but also as water necessary to coating to reach the right mechanical properties during the sowing to allow sprouting. As confirmation, in this 
study, from the mechanical characterization of the coating emerged a higher germination rate was registered in correspondence of a strong decrease in tensile strength and reduction in deformation at break i.e. in conditioned 70/30 ratio sample. Differently, 50/50 ratio samples whilst showing close mechanical properties to 70/30, allowed a lower water permeation and showed an inferior germination rate. This lead to suppose the right balance between water permeability and mechanical properties influences the germination rate.

In conclusion, although it was not possible to establish a strong correlation between the mechanical properties of the material and germination it is plausible to hypothesize that if the impermeability and mechanical properties of the coating are high, the seed has difficulty in sprouting.

Moving from these results, new tests could be carried out to optimize the properties of the coating in order to obtain the right compromise between the barrier effect to substances harmful to the seed, water uptake and mechanical properties to facilitate germination. Finally, CA/Card blend optimization could play an important role also in other field than seed coating, since it could lead to a new perspective in waste reuse such as cigarette filters, possibly after a process of washing and removing toxic substances.

Acknowledgements Open access funding provided by Università del Salento within the CRUI-CARE Agreement. Thanks to Mr. Donato Cannoletta for SEM sessions and to Mr. Francesco Montagna for help in climatic chamber use.

Author Contributions The manuscript and all the changes were written through contributions of all authors. All authors have given approval to the final version of the manuscript.

Funding Industrial PhD Program: "Dottorati innovative a caratterizzazione industriale".

\section{Compliance with Ethical Standards}

Conflict of interest The authors declare no competing financial interest. The datasets generated during and/or analyzed during the current study are available from the corresponding author on reasonable request.

Open Access This article is licensed under a Creative Commons Attribution 4.0 International License, which permits use, sharing, adaptation, distribution and reproduction in any medium or format, as long as you give appropriate credit to the original author(s) and the source, provide a link to the Creative Commons licence, and indicate if changes were made. The images or other third party material in this article are included in the article's Creative Commons licence, unless indicated otherwise in a credit line to the material. If material is not included in the article's Creative Commons licence and your intended use is not permitted by statutory regulation or exceeds the permitted use, you will need to obtain permission directly from the copyright holder. To view a copy of this licence, visit http://creativecommons.org/licenses/by/4.0/.

\section{References}

1. Maggi F (2020) The global environmental hazard of glyphosate use. Sci Total Environ 717:137-167

2. Mohammadi GR (2013) In: Soloneski S (ed) Weed and pest control-conventional and new challenges. IntechOpen, London, pp 117-159

3. Food and Agriculture Organization of the United Nations (FAO) (2007) Recommendations for improved weed management. Food and Agriculture Organization of the United Nations (FAO), Rome

4. Melander B (2005) Integrating physical and cultural methods of weed control: examples from European research. Weed Sci 53(3):369-381

5. Kraehmer H (2014) Herbicides as weed control agents: state of the art: I. Weed control research and safener technology: the path to modern agriculture. Plant Physiol 166(3):1119-1131

6. Rosaria C (2019) Herbicides based on pelargonic acid: herbicides of the bioeconomy. Biofuels Bioprod Biorefin 13(6):1476-1482

7. Coleman R (2008) Organic acid enhancement of pelargonic acid. Weed Technol 22(1):38-41

8. Wehtje G (2009) Interaction of glyphosate and pelargonic acid in ready-to-use weed control products. Weed Technol 23(4):544-549

9. Webber CL (2014) Weed control in yellow squash using sequential postdirected applications of pelargonic acid. Hortic Technol 24(1):25-29

10. Webber CL (2006) Pelargonic acid weed control parameters. Hortic Sci 41(4):1034

11. Pline WA (2000) Weed and herbicide-resistant soybean (Glycine max) response to glufosinate and glyphosate plus ammonium sulfate and pelargonic acid. Weed Technol 14(4):667-674

12. Cullen MG (2019) Fungicides herbicides and bees: a systematic review of existing research and methods. PLoS ONE 14(12):1-17

13. Tworkoski $\mathrm{T}$ (2002) Herbicide effects of essential oils. Weed Sci 50(4):425-431

14. Benvenuti S (2017) Weeds for weed control: Asteraceae essential oils as natural herbicides. Weed Res 57:342-353

15. Ibáñez MD (2018) Phytotoxicity of essential oils on selected weeds: potential hazard on food crops. Plants 7(4):79

16. Bleadsale $\mathbf{J}$ (1956) Interspecific competition in higher plants. Nature 178(4525):150-151

17. Kolb LN (2010) Improving weed management in organic spring barley: physical weed control vs. interspecific competition. Weed Res 50:597-605

18. Park SE (2003) The theory and application of plant competition models: an agronomic perspective. Ann Bot 92(6):741-748

19. Thiel C (2018) Physiology of weeds in intraspecific competition. J Agric Sci 10:334

20. Rocha I (2019) Seed coating: a tool for delivering beneficial microbes to agricultural crops. Front Plant Sci 10:1357

21. Simone $P$ (2017) Seed coating: science or marketing spin? Trends Plant Sci 22(2):106-116

22. Mordor Intelligence (2020) Seed coating material marketgrowth, trends and forecast (2020-2025). Market Research report

23. Avelar SAG (2012) The use of film coating on the performance of treated corn seed. RBS 34:186-192

24. Halmer P (2008) Seed technology and seed enhancement. Acta Hortic 771:17-26

25. Menz MHM (2013) Hurdles and opportunities for landscape-scale restoration. Science 339:526-527

26. Scott JM (1989) Seed coatings and treatments and their effects on plant establishment. Adv Agron 42:43-83

27. Schneider A (1997) Effects of coating on seed imbibition: I. Model estimates of water transport coefficient. CSSA 37(6):1841-1849 
28. Accinelli C (2019) Degradation of microplastic seed film-coating fragments in soil. Chemosphere 226:645-650

29. Fischer S (2008) Properties and applications of cellulose acetate. Macromol Symp 262:89-96

30. Harris L (2004) The production of strong, cellulose acetate films. Rev Sci Instrum 4(8):454-455

31. Puls SAJ (2011) Degradation of cellulose acetate-based materials: a review. J Polym Environ 19:152-165

32. Buchanan CM (1993) Aerobic biodegradation of cellulose acetate. J Appl Polym 47:1709-1719

33. Gu J-D (1993) Cellulose acetate biodegradability upon exposure to simulated aerobic composting and anaerobic bioreactor environments. J Environ Polym Degrad 1(2):143-153

34. Buchanan CM (1993) Aerobic biodegradation of cellulose acetate. J Appl Polym Sci 47:1709-1719

35. Gardner RM (1994) Compostability of cellulose acetate films. J Appl Polym Sci 52:1477-1488

36. Van der Zee M (1998) Relevance of aquatic biodegradation tests for predicting biodegradation of polymeric materials during biological solid waste treatment. Chemosphere 36(3):461-473

37. Northrop DM (1987) Effect of the soil environment on the biodeterioration of man-made textiles. Int Biodeterior Biodegrad $1: 7-16$

38. Hon NS (1977) Photodegradation of cellulose acetate fibers. J Appl Polym Sci 15:725-744

39. Vos KD (1966) Kinetic study of the hydrolysis of cellulose acetate in the $\mathrm{pH}$ range of 2-10. J Appl Polym Sci 10:825-832

40. Kumar PP (2002) Process for isolation of cardanol from technical cashew (Anacardium occidentale L.) nutshell liquid. J Agric Food Chem 50:4705-4708

41. Lubi MC (2000) Cashew nut shell liquid (CNSL) - a versatile monomer for polymer synthesis. Des Monomers Polym 3(2):123-153
42. Greco A (2018) Use of cardanol derivatives as plasticizers for PVC. J Vinyl Addit Technol 24:62-70

43. Greco A (2020) Compression behavior of soft PVC foams obtained by cardanol-derived plasticizer. J Cell Plast. https://doi. org/10.1177/0021955X20912202

44. Maffezzoli A (2004) Cardanol based matrix biocomposites reinforced with natural fibers. Compos Sci Technol 64:839-845

45. Robertson RM (2012) Accelerated degradation of cellulose acetate cigarette filters using controlled release acid catalysis. Curr Green Chem 14:2266

46. Mohajerani A (2016) A practical proposal for solving the world's cigarette butt problem: recycling in fired clay bricks. J Waste Manag 52:228-244

47. Dimida S (2017) Effects of Genepin concentration on cross-linked chitosan scaffolds for bone tissue engineering: structural characterization and evidence of biocompatibility features. Int J Polym Sci. https://doi.org/10.1155/2017/8410750

48. Cannazza G (2014) Experimental assessment of the use of a novel superabsorbent polymer (SAP) for the optimization of water consumption in agricultural irrigation process. Water 6(7):2056-2069

49. Pamuk GS (2002) Evaluation of polymer coating on Scots Pine (Pinus sylvestris) seeds using scanning electron microscopy (SEM). Seed Sci Technol 30(1):167-176

50. Shiddanagouda $Y$ (2012) Development of seed coating technology for carrot seed. Environ Ecol 30(3A):798-801

51. Ochica AF (2017) Obtention of cellulose acetate nanofibers from sugar cane bagasse. Cienc Desarro 8(2):69-77

Publisher's Note Springer Nature remains neutral with regard to jurisdictional claims in published maps and institutional affiliations. 